\title{
Frustration effect after development of patterned responding to single-alternation reinforcement*
}

\author{
JAMES J. HUG \\ University of Toronto, Toronto, Canada
}

Using a 20-min ITI, one group received single-alternation partial reinforcement in the first alley of a double-runway apparatus. A second group also ran to a single-alternation schedule in Alley 1, but did not run in Alley 2. Results indicated that single vs double alley running did not affect the rate of development, or the terminal strength, of patterned responding. A substantial decrease in the magnitude of the frustration effect occurred in the second alley as patterning developed in the first.

The frustrative nonreward account of discrimination learning (Amsel, 1958) posits four discrete stages in the formation of a discrimination. During the first three stages, the discriminanda do not operate differentially. In the first stage, the developing, but yet weak, strength of expectancy $\left(r_{R}-S_{R}\right)$ is insufficient to elicit primary frustration $\left(R_{F}\right)$ on nonrewarded trials. After $R_{F}$ is elicited on nonrewarded trials during the second stage, a conditioned form of the frustration reaction $\left(\mathrm{r}_{\mathrm{F}}-\mathrm{s}_{\mathrm{F}}\right)$ develops during the third stage and produces conflict: both $\mathrm{S}^{+}$and $S-$ elicit $r_{R}-s_{R}$ and $r_{F}-s_{F}$, the former signaling approach to the goal and the latter signaling avoidance of it. This conflict is resolved and the discrimination formed in the final (fourth) stage. Now only $r_{R} \cdot s_{R}$ and approach are elicited by $S+$, and similarly only $\mathrm{r}_{\mathrm{F}}$-SF and avoidance are elicited by $\mathrm{S}-$.

This theory has implications for the frustration effect (FE), by which the strength of $R_{F}$ is inferred. The $F E$ is measured in a double-runway apparatus, in which performance in the second runway is contrasted after reward and nonreward in the first; the characteristic finding is one of more vigorous running, purportedly due to the nonspecific energizing effect of $R_{F}$, after nonrewarded first-runway trials. If $\mathrm{S}+$ and $S$ - trials are given in the first runway and the FE measured in the second, the magnitude of the FE should increase at first, as the strength of $r_{R} \cdot s_{R}$ on $S$ - trials becomes sufficient to elicit $R_{F}$, and then becomes stronger, resulting in a more intense $R_{F}$. Later on, however, when the final hypothetical stage is reached, the magnitude of the FE should be reduced, if

*Supported by Research Grants GB-3772 from the National Science Foundation and APA-72 from the National Research Council of Canada, both of which were awarded to Professor Abram Amsel. This experiment was conducted according to the APA statement of "Principles for the Care and Use of Animals," June 26, 1968, Reprint requests should be sent to Department of Correctional Services, Research Branch. Parliament Buildings, Toronto, Canada. not in fact eliminated entirely, since $S-$ no longer elicits the expectancy required (Amsel, 1958) for nonreward to be "frustrating." This prediction has been confirmed by Amsel \& Ward (1965, Experiment 1) for a black-white discrimination.

The present investigation sought to extend this finding to a different type of "discrimination," one in which no discriminanda are provided by the E. Recent experimentation (e.g., Bloom \& Capaldi, 1961; Capaldi \& Stanley, 1963) has shown that when the reinforced and nonreinforced $t r i a l s$ of a partial-reinforcement schedule to one stimulus are "patterned," for example, when $\mathrm{R}$ and $\mathrm{N}$ trials follow a single-alternation sequence, $\mathrm{S}$ is able to differentiate $\mathrm{R}$ and $\mathrm{N}$ trials and respond accordingly.

\section{METHOD}

Twenty male albino rats of the Wistar strain were obtained from Woodlyn Farms, Guelph, Ontario, and were approximately $80-90$ days old on arrival. They were immediately placed on a $12 \cdot \mathrm{g} / 23 \cdot \mathrm{h}$ food-deprivation schedule, given $30 \mathrm{~min}$ after completion of the daily sessions, with free access to water. The Ss were handled $1 \mathrm{~min}$ daily during the 8 days prior to pretraining.

An L-shaped double-alley runway was used. Alley 1 was painted flat black and contained in series: an 11-in. entrybox, 11-in. startbox, and 47-in. alley. Guillotine doors separated the start and entry chambers and formed a 21-in. goalbox (GB). The food pellet was concealed in a small black cup placed approximately $2 \frac{1}{2}$ in. above the runway floor on the side of the end wall opposite the door leading to Alley 2. Alley 2 was placed perpendicular to Alley 1 , was 45 in. long, unpainted pine, and had a hardware cloth floor and a 14-in. GB. Guillotine doors controlled access to Alley 2 and formed the GB. In the second runway, the food pellet was concealed in a grey metal trough, extending the length of the end wall at a height of $2 \frac{1}{2}$ in. above the floor. Both runways were covered with clear Plexiglas and were $2-7 / 8$ in. wide $x$ $3.7 / 8$ in. high. Microswitches on the start doors, silent photoelectric circuitry, and $.01-\mathrm{sec}$ clocks were used to obtain $1-\mathrm{ft}$ measures of response time. In Alley 1, these measures were obtained over the first

Table 1

Performance of Group D Over Blocks of Trials (Days)

\begin{tabular}{|c|c|c|c|c|c|}
\hline \multirow[b]{3}{*}{ Block } & \multicolumn{4}{|c|}{ FE Magnitude. Alley 2} & \multirow{3}{*}{$\begin{array}{c}\text { Magnitude of } \\
\text { Patterning } \\
\text { Alley } 1 \\
\end{array}$} \\
\hline & \multicolumn{2}{|c|}{ Start } & \multicolumn{2}{|c|}{ Run } & \\
\hline & Obs. & Est. & Obs. & Est. & \\
\hline 1 & -.06 & -.20 & .03 & -.18 & .02 \\
\hline 2 & -.11 & -.10 & -.04 & -.07 & .17 \\
\hline 3 & .08 & -.01 & .01 & .03 & -.08 \\
\hline 4 & -.04 & .07 & -.01 & .12 & .12 \\
\hline 5 & -.10 & .14 & .18 & .21 & .08 \\
\hline 6 & .18 & .21 & .30 & .28 & -.09 \\
\hline 7 & .20 & .27 & .23 & .35 & -.09 \\
\hline 8 & .31 & .33 & .38 & .41 & -.02 \\
\hline 9 & .42 & .37 & .28 & .46 & -.02 \\
\hline 10 & .39 & .41 & .37 & .51 & .02 \\
\hline 11 & .50 & .45 & .56 & .54 & .09 \\
\hline 12 & .58 & .47 & .55 & .57 & -.04 \\
\hline 13 & .62 & .49 & .73 & .59 & -.08 \\
\hline 14 & .63 & .50 & .61 & .60 & .06 \\
\hline 15 & .67 & .51 & .79 & .60 & .22 \\
\hline 16 & .45 & .51 & .80 & .60 & .23 \\
\hline 17 & .48 & .50 & .60 & .58 & .22 \\
\hline 18 & .39 & .49 & .62 & .56 & .41 \\
\hline 19 & .31 & .46 & .69 & .53 & .53 \\
\hline 20 & .34 & .44 & .26 & .50 & .47 \\
\hline 21 & .30 & .40 & 41 & .45 & .63 \\
\hline 22 & .38 & .36 & .30 & .40 & .67 \\
\hline 23 & .35 & .31 & .21 & .33 & .60 \\
\hline 24 & .37 & .25 & .37 & .26 & .77 \\
\hline
\end{tabular}

Note. All data are in feet per sciond, comparing the tho $R$ or TFR trials of any day with the two $N$ or TFN irtals. 
Table 2

Individual-Subject Data for Group D

\begin{tabular}{|c|c|c|c|c|}
\hline \multirow[b]{2}{*}{$S$} & \multicolumn{3}{|c|}{ FE Magnitude, Alley 2} & \multirow{2}{*}{$\begin{array}{c}\text { Patterning } \\
\text { Alley } 1 \\
\text { Days 22-24 }\end{array}$} \\
\hline & $\begin{array}{r}\text { Days } \\
14-16\end{array}$ & $\begin{array}{l}\text { Days } \\
22-24\end{array}$ & $\begin{array}{l}\text { Diffe- } \\
\text { rence }\end{array}$ & \\
\hline 1 & 1.28 & .59 & .69 & .87 \\
\hline 2 & .25 & .38 & -.13 & .66 \\
\hline 3 & .51 & -.02 & .53 & .98 \\
\hline 4 & 1.15 & .62 & .53 & .78 \\
\hline 5 & -.02 & -.33 & .31 & .77 \\
\hline 6 & 1.06 & .89 & .17 & .90 \\
\hline 7 & .77 & .53 & .24 & .62 \\
\hline 8 & .35 & -.13 & .48 & .55 \\
\hline 9 & .42 & .47 & -.05 & -.07 \\
\hline 10 & .73 & .28 & .45 & .74 \\
\hline
\end{tabular}

Note-All data are in feet per second, compar. ing the two $R$ or TFR trials of any day with the two $N$ or TFN trials.

36 in. of the runway; in Alley 2, measures were obtained over the first 24 in.

The Ss were assigned randomly to one of two groups on arrival. Group D received $50 \%$ partial reinforcement, using an $\mathrm{R}-\mathrm{N}$ single-alternating sequence, in $\mathrm{GB} 1$ and continuous reinforcement in GB2. Group S was run under identical Alley 1 conditions, but did not traverse Alley 2. The latter group was included against the possibility that the development of patterned responding in Alley 1, which has been somewhat difficult to obtain in the Toronto laboratory, might be obscured by having $S$ run to a different schedule in Alley 2.

Four trials were run each day, separated by an ITI of approximately $20 \mathrm{~min}$. A single Noyes pellet of $300 \mathrm{mg}$ was used as reinforcement in both GBs. A total of 96 acquisition trials were administered. Since all $S s$ received the same reinforcement schedule in the first runway, any given experimental trial consisted solely of an $\mathrm{R}$ or an $\mathrm{N}$ event in GB1. The Ss were run as a single squad. One of three random running orders was used once, randomly, in any 3-day block; the same running order was followed on all four trials of any experimental day. Prior to Trial 1, all Ss received three 5 -min daily periods of runway habituation, in pairs, during which time all doors were retracted and the recording circuitry was operative. No food was given in relation to handling or pretraining.

On every trial, $S$ was released into Alley 1 after orienting to the start door. On rewarded GB1 trials, $S$ was released into the second alley (Group D), or removed from GBl (Group S), 5 sec after completion of eating; approximately $15 \mathrm{sec}$ were required to consume the pellet. On nonrewarded GBI trials, $S$ was released into Alley 2 (Group D), or removed (Group S), after a 20-sec confinement to GB1. The Ss in Group D were removed from GB2 upon completion of eating. The first GB was false-baited on $N$ trials. and was always surrounded by crumbled pellets, to minimize S's detection of the presence of the pellet.

\section{RESULTS AND DISCUSSION}

Performance in the first alley (discrimination) was gauged by calculating total alley speed, i.e., the reciprocal of the sum of the three separate latencies. For second-alley data (frustration effect), reciprocal transformations were applied to the uncombined latency measures.

Analysis of variance was imposed on Alley 1 data to determine the extent to which Ss patterned and the effect of singlevs double-alley running on patterning. In addition to a significant days effect, $F(23,414)=500.34, \quad p<.01, \quad$ reliable Groups by Days, $F(23,414)=4.52$. $\mathrm{p}<.01$, and Goal Event by Days, $\mathrm{F}(23,414)=16.66, \quad \mathrm{p}<.01$, interactions were present. The former interaction resulted from the terminal superiority of Group S, which was not apparent earlier in acquisition, while the latter was a consequence of the gradual development of patterned responding. Thus, although the performance of Group D was relatively depressed late in acquisition, there was no evidence of group differences in the amount of patterning, in the form of Groups by Goal Event or Groups by Goal Event by Days interactions.

The FE was present in both measures of Alley 2 performance, $F(1,9)=53.75$ and 18.39 , respectively, both $p<.01$, but the magnitude of this effect varied substantially as a function of days, $\mathrm{F}(23,207)=9.25$ and 6.96 , respectively, both $\mathrm{p}<.01$.

Table 1 presents $\mathrm{FE}$ magnitude data across days along. with least-squares estimates of the function, $M=a N^{2}+b N+c$, where $M$ denotes $F E$ magnitude, $\mathrm{N}$ denotes days, and $\mathrm{a}, \mathrm{b}$, and $\mathrm{c}$ represent the constants to be estimated. Patterning data are also presented for comparison. Examination of these latter data indicates that patterning was consistently present from Day 14 (Trial 53) on. (As is rather typical in discrimination learning, the development of patterning resulted from decreasingly vigorous performance to "S-" after an initial period of nondifferentiation.) Using this point as the formation of the "discrimination," FE magnitudes were compared during Days 14-16 and during the final 3 days $(22-24)$. For both measures, the decrease in FE magnitude exceeded that attributable to chance, $F(1,207)=4.15, \quad p<.05$, and 12.08, $p<.01$, respectively. Despite these reductions, the magnitude of the $\mathrm{FE}$ remained above zero $(p<.05)$ during the final 3 days. That this reduction resulted from some change in the functional consequences of first-alley nonreward, and not reward, was shown by the tendency for Alley 2 speeds on trials following reward to increase over these days, although not signiticantly so $(\mathrm{p}>.10)$. The nonlinear relationship between $\mathrm{FE}$ magnitude and days was further apparent in the least-squares functions which, mathematically, reached their maxima during the 15th and 14th days. respectively.

Table 2 indicates that this phenomenon is not the result of one or two aberrant Ss. Nine of the 10 Ss (Group D) displayed patterning, when the $\mathrm{R}$-- $\mathrm{N}$ difference was taken over the final 3 days. The $S$ that did not pattern did not display reduced $\mathrm{FE}$ magnitude. Of the nine $S s$ that did "discriminate," eight had a lower FE magnitude over Days 22-24 than over Days 14-16. The correlation between the reduction of $F E$ magnitude and magnitude of patterning was rather large, $r_{x y}=.566$, and positive, but was not reliable $(\mathrm{p}>.05)$ in view of the small $\mathrm{df}$.

The present data suggest that the Amsel \& Ward (1965) finding is applicable to situations in which $E$ does not provide discriminanda. The procedure used here was deliberately chosen to maximize the possibility of appearance of patterning in the first alley, and, unfortunately, does not allow for the isolation of the source of this incidental discrimination. Since any given trial consisted solely of $\mathrm{R}$ or solely of $\mathrm{N}$ events, it is not possible to state whether the patterning observed in this study was the result of stimulus aftereffects (e.g.. Capaldi, 1966) or of "odor" cues (e.g., McHose \& Ludvigson, 1966) left by previous Ss, which under certain conditions can be discriminative even when stimulus aftereffects are not predictive.

\section{REFERENCES}

AMSEL, A. The role of frustrative nonreward in noncontinuous reward situations. Psychological Bulletin, 1958, 55, 102-119.

AMSEL, A., \& WARD, J. S. l'rustration and persistence: Resistance to discrimination following prior experience with the discriminanda. Psychological Monographs, $1965,79(4$, Whole No. 597).

BLOOM, J. M., \& CAPALDI, F. J. The behavior of rats in relation to complex patterns of partial reinforcement. Journal of Comparative \& Physiological Psychology, 1961, 54 261-265.

CAPALDI, E. J. Partial reinforcement: A hypothesis of sequential effects. Psychological Review, 1966. 73, 459-477.

CAPALDI, E. J., \& STANLEY, L. R. Temporal properties of reinforcement aftereffects. Journal of Experimental Psychology, 1963 65, 169-175.

McHOSE, J. H., \& LUDVIGSON, H. W. $\mathrm{D}^{\mathrm{r} r}$ rential conditioning with nondifferential reinforcement. Psychonomic Science, 1966, 6, 485-486. 